Int. J. Electrochem. Sci., 15 (2020) 1450 - 1464

International Journal of

ELECTROCHEMICAL

SCIENCE

www.electrochemsci.org

\title{
Preparation and Corrosion Resistance of AKT-Waterborne Polyurethane Coating
}

\author{
Xia Wang*, Li Hou, Ling-long Xu, Xiong Li, Huan Jiang, Wen-jie Zhou \\ School of Material Science and Engineering, Southwest Petroleum University, Chengdu 610500, \\ People's Republic of China \\ *E-mail:hli0825@163.com
}

doi: $10.20964 / 2020.02 .28$

Received: 30 September 2019 / Accepted: 19 November 2019 / Published: 31 December 2019

In this paper, an inorganic-organic composite modification of nano- $\mathrm{TiO}_{2}$ has been carried out using aluminum sulfate octahydrate and $\gamma$-aminopropyltriethoxysilane (KH550) to obtain AKT with good dispersion performance. The AKT-WPU composite coating with different amounts of nano- $\mathrm{TiO}_{2}$ added was prepared by blending AKT with waterborne polyurethane (WPU). The nano- $\mathrm{TiO}_{2}$, before and after modification, was analyzed by Fourier transform infrared spectroscopy and indicates that alumina and KH550 can be successfully grafted onto the surface of nano- $\mathrm{TiO}_{2}$. Our thermogravimetric analysis shows that the heat resistance of the AKT-WPU composite coating was improved. The corrosion resistance of the AKT-WPU composite coatings was investigated by electrochemical impedance spectroscopy and polarization curves. Our results show that the addition of AKT significantly improves the corrosion resistance of the composite coating. The resistive modulus of the composite coating with $0.7 \%$ AKT addition amounted to $5.05 \times 10^{6} \Omega$. The corrosion current density is $5.21 \times 10^{-9} \mathrm{~A}$, which is more than two orders of magnitude lower than that with the pure WPU coating. The corrosion inhibition efficiency can reach $99.54 \%$. The coating was subjected to a long-term immersion test and observed by a scanning electron microscope. After immersion for $360 \mathrm{~h}$, our results show that the coating still protected the stainless steel.

Keywords: nano- $\mathrm{TiO}_{2}$; waterborne polyurethane; corrosion resistance

\section{FULL TEXT}

(C) 2020 The Authors. Published by ESG (www.electrochemsci.org). This article is an open access article distributed under the terms and conditions of the Creative Commons Attribution license (http://creativecommons.org/licenses/by/4.0/). 